\title{
Comparison of FFT and marginal spectra by Hilbert-Huang transform for broadband spectral analysis of EEG
}

\author{
Eduardo Arrufat-Pié ${ }^{1}$, Mario Estévez-Báez ${ }^{2}$, José Estévez-Carreras ${ }^{3}$, Calixto \\ Machado-Curbelo ${ }^{2}$, Gerry Leisman ${ }^{4}$, and Carlos Beltrán ${ }^{2}$ \\ ${ }^{1}$ Hospital Comandante Manuel Fajardo \\ ${ }^{2}$ Instituto de Neurologia y Neurocirugia \\ ${ }^{3}$ Hospital Militar Dr. Luis Díaz Soto \\ ${ }^{4}$ University of Haifa
}

August 4, 2020

\begin{abstract}
Goal: Fast Fourier transform (FFT), has been the main tool for EEG spectral analysis (SPA). As EEG can show nonlinear and non-stationary behavior, FFT may at times be meaningless. A novel method was developed for analyzing nonlinear and non-stationary signals using the Hilbert-Huang transform. Methods: We compared spectral analyses of EEG using FFT with Hilbert marginal spectra (HMS) with a multivariate empirical mode decomposition algorithm. Segments of continuous 60-sec EEGs recorded from 19 leads of 47 healthy volunteers were studied. Results: HMS showed a reduction of the alpha activity $(-5.64 \%)$, with increments in the beta-1 $(+1.67 \%)$, and gamma $(+1.38 \%)$ fast activity bands, an increment in theta $(+2.14 \%)$, and in delta $(+0.45 \%)$ bands, and vice versa for the FFT method. For weighted mean frequencies, insignificant mean differences (lower than $1 \mathrm{~Hz}$ ) were observed between both methods for delta, theta, alpha, beta-1 and beta-2 bands, and only for gamma band values. The HMS were $3 \mathrm{~Hz}$ higher than the FFT method. Conclusion: HMS may be considered a good alternative for SPA of the EEG when nonlinearity or non-stationarity may be present.
\end{abstract}

\section{Hosted file}

2020-Arrufat-Pie-Estevez-Leisman-NumMethods-EEG-Normal.docx available at https://authorea. com/users/348645/articles/473851-comparison-of-fft-and-marginal-spectra-by-hilberthuang-transform-for-broadband-spectral-analysis-of-eeg 

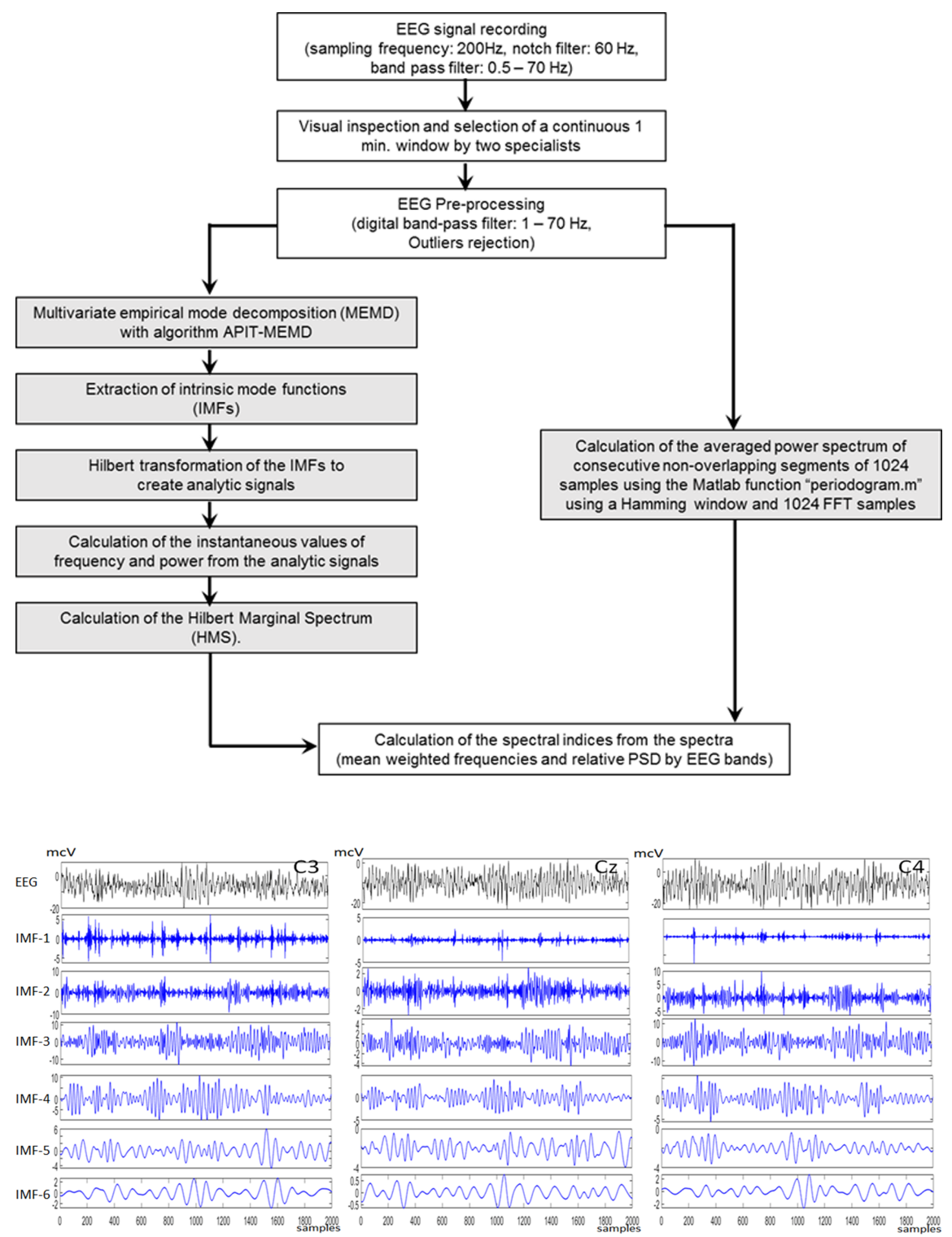

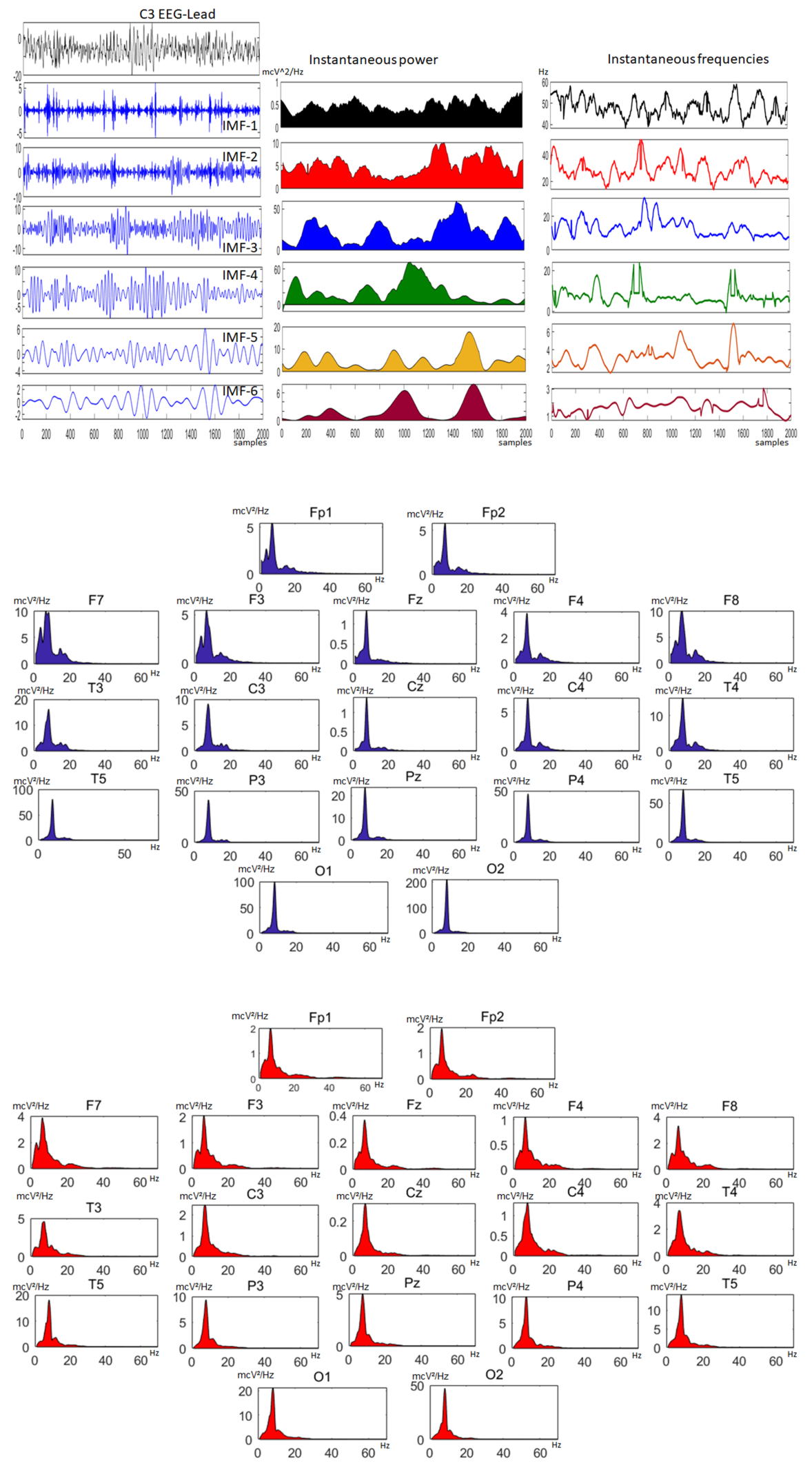

3 

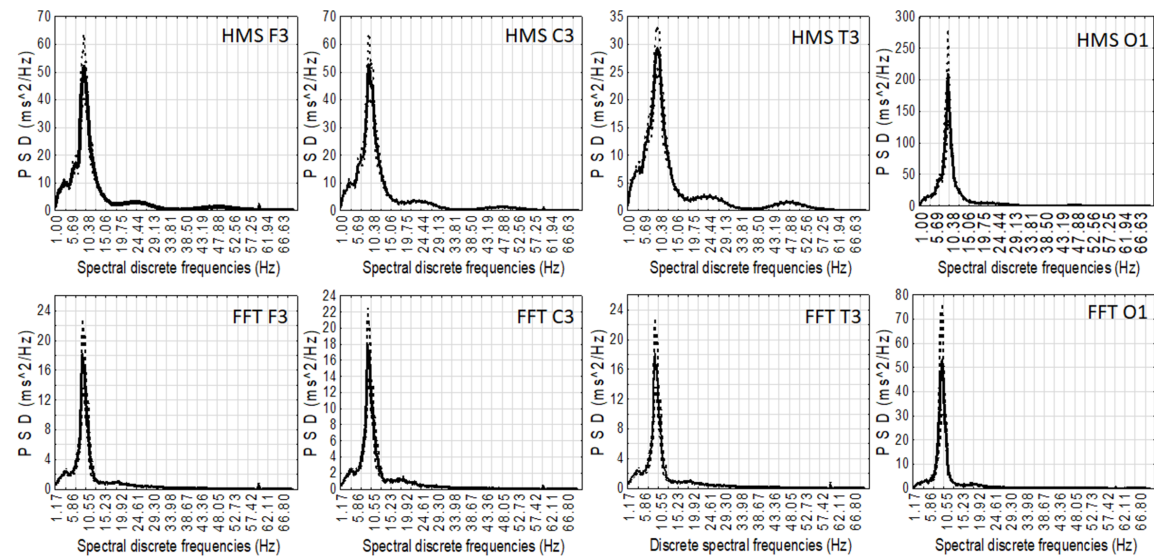